\title{
TEMPOS DE MUDANÇAS E SUAS ADAPTAÇÕES
}

\section{Maíra Bonafé Sei}

Universidade Estadual de Londrina

Maria Lúcia Mantovanelli Ortolan

Universidade Estadual de Londrina

\section{Nathália Tavares Bellato Spagiari}

Universidade Estadual de Londrina

A pandemia da COVID-19 demandou uma adaptação das pessoas no campo do trabalho, das relações familiares e sociais, tendo a morte presente em nossas vidas de uma maneira talvez não vivenciada anteriormente, principalmente pelas novas gerações. Tal contexto pode contribuir para reflexões acerca daquilo que priorizamos em nossa existência. Assim, com quais atividades e relações nossa vida tem sido preenchida? Questionamentos como esse indagam sobre os ajustes que podemos fazer em prol de um viver mais saudável e portador de sentido. $\mathrm{E}$ tais mudanças fizeram-se presentes na revista Estudos Interdisciplinares em Psicologia, com a saída da colega Profa. Dra. Patricia Silva Lúcio do cargo de editora-chefe.

Muitas foram as contribuições da Profa. Patricia ao longo dos anos em que esteve inserida na revista, que englobam desde o desenvolvimento de um novo logotipo da revista, layout do modelo de artigo e atualização dos formulários de avaliação. Delineou, ademais, um projeto de formação complementar que visa a capacitação de discentes de graduação, pós-graduação e demais tipos de colaboradores, desenvolvendo uma rede de colaboração para a realização das tarefas editoriais. Sua disposição, envolvimento, encanto e leitura crítica nos fará falta e desejamos que os novos caminhos possam ser mais leves que a árdua e pouco reconhecida atuação como editora-chefe.

As mudanças demandaram um tempo para que a equipe pudesse se reorganizar, finalizar o trâmite dos artigos e relatos de experiência outrora submetidos, que implicou na suspensão das submissões por um tempo mais amplo que aquele inicialmente previsto. Essa suspensão gerou, igualmente, ponderações na equipe editorial, agora composta pelas profissionais Maíra Bonafé Sei, Maria Lúcia 
Mantovanelli Ortolan e Nathália Tavares Bellato Spagiari, que aponta para outras estratégias de funcionamento do periódico, tais como o estabelecimento de prazos específicos para as submissões, sem o anterior fluxo contínuo adotado desde o início da revista.

Além da homenagem à Profa. Patrícia e da ênfase de que ela nos fará falta, em tempos pandêmicos, nos quais ainda somos surpreendidos a cada dia pelos crescentes números de mortes, cabe a esse editorial também reiterar a importância dos avanços da ciência, esta que vem até então sendo tão negada. Foi com muita satisfação e renovação de esperança, que recebemos artigos, ainda em fase de tramitação, tangenciando a temática da COVID-19, principalmente em relação à saúde mental. Enquanto pesquisadores interessados e comprometidos com o ser humano e a qualidade de seu (bem ou mal) estar no mundo, estamos honrados em poder veicular o conhecimento científico e, assim, reafirmar sua importância para a reconstrução e evolução do mundo.

Nesta mesma linha, gostaríamos também de agradecer imensamente aos colegas que, na posição de pareceristas dos manuscritos, não hesitaram, mesmo em tempos tão exaustivos e cheio de angústias, em continuar seus trabalhos em prol da construção e do aprimoramento do conhecimento científico. Sem esta resistência, necessária, frente à descredibilização e precarização da ciência e do trabalho acadêmico não conseguiremos avançar.

Boa leitura!

\section{GERÊNCIA DE EDITORAÇÃO}

Dra. Maíra Bonafé Sei, Universidade Estadual de Londrina, Brasil

\section{CONSELHO EDITORIAL}

Dra. Acácia Aparecida Angeli dos Santos, Universidade São Francisco, Brasil Dra. Alexandra Anache, Universidade Federal de Mato Grosso do Sul, Brasil Dra. Andrea Bustos Ibarra, Pontificia Universidad Católica de Valparaíso, Chile Dra. Evely Boruchovitch, Universidade de Campinas, Brasil

Dr. Manoel Antônio dos Santos, Universidade de São Paulo (Ribeirão Preto), Brasil

Dr. Roberto Calazans, Universidade Federal de São João Del Rey, Brasil

Dr. Sebastián Urquijo, Universidad Nacional de Mar Del Prata, Argentina

\section{COMISSÃO EDITORIAL}

Maria Lúcia Mantovanelli Ortolan, Universidade Estadual de Londrina Nathália Tavares Bellato Spagiari, Universidade Estadual de Londrina

\section{APOIO TÉCNICO}

Ana Carolina Moraes Silva, Universidade Estadual de Londrina 